\title{
INNOMINATE OSTEOTOMY IN THE TREATMENT OF CONGENITAL DISLOCATION AND SUBLUXATION OF THE HIP*
}

\author{
Robert B. Salter, Toronto, Canada \\ From the Department of Surgery, University of Toronto, and the Hospital for Sick Children, Toronto
}

The purpose of this paper is to describe a method of overcoming the instability of reduction in congenital dislocation and subluxation of the hip in children over the age of eighteen months. Despite the emphasis on early diagnosis and treatment, and although there is a great increase in the number of infants referred early, a disturbing number of children still remain undiagnosed until some time after they have learned to walk. It is with this group, over the age of eighteen months, that the present paper is concerned.

Throughout this paper a distinction will be made between congenital dislocation and congenital subluxation. During the first few months of life a subluxation of the hip may either become a dislocation or remain a subluxation; by eighteen months, however, an untreated hip that is still subluxated is likely to remain as a subluxation. In the age group under consideration the two conditions exhibit certain differences in their pathology which must be taken into consideration during treatment.

\section{THE PROBLEM OF INSTABILITY OF REDUCTION}

Initial reduction of the congenital dislocation between the ages of eighteen months and six years can usually be obtained by a period of traction followed by either closed or open reduction. In congenital subluxation, on the other hand, reduction occurs with simple abduction and flexion of the hip. The main problem is not the reduction but the instability of reduction in both congenital dislocation and congenital subluxation. The reduced hip is stable in a position of abduction, flexion and varying degrees of rotation; however, the hip is unstable and either redislocates or resubluxates when the limb is brought back into the functional position of walking.

During the first twelve months of life the problem of instability of the reduced hip can usually be overcome by maintaining the hip in a stable position for a period of a relatively few months. During this period normal-or nearly normal-osseous development of the cartilage model of the acetabulum and femoral head can be expected to take place; consequently the reduced hip eventually becomes stable even in the functional position of walking. This potential for normal osseous development after reduction of the dislocation or subluxation is greatest at birth and gradually decreases thereafter; by contrast, as long as the hip remains unreduced, the secondary changes-which are minimal at birth-become progressively more marked. Because of the combination of these two factors, the possibility of reversing these secondary changes diminishes fairly rapidly. Indeed, by about eighteen months of age, normal osseous development of the acetabulum and femoral head is no longer assured even by prolonged retention of the reduced hip in a stable position.

If treatment of congenital dislocation or congenital subluxation has not stimulated adequate osseous development the hip is seldom stable in the functional position of walking. Furthermore, once weight bearing is allowed normal osseous development of the acetabulum and femoral head can continue only if the reduction remains completely stable. Even a slight residual or recurrent subluxation gradually becomes worse with weight bearing, with the result that further osseous development is imperfect and there ensues a gradual deterioration

\footnotetext{
* Read at the Annual Meeting of the Canadian Orthopaedic Association, Waskesiu, June 1960, and also summarised at the eighth Congress of the International Society of Orthopaedic Surgery and Traumatology, New York, 1960.
} 
of the function of the hip. This unfavourable sequence of events is readily seen by studying the consecutive radiographs of a large number of patients in whom treatment was instituted after the age of eighteen months.

\section{EXISTING METHODS OF OVERCOMING THE INSTABILITY OF REDUCTION}

Many and varied are the methods of treatment designed to provide stability of the reduced congenital dislocation and congenital subluxation in children over the age of eighteen months. These methods may be considered in three main groups, any of which may be combined: prolonged retention of reduction in a stable position, operations on the femur, and operations on the pelvis.

Prolonged retention of reduction in a stable position-This method, effective in infants during the first twelve months of life, gradually becomes less effective, especially after eighteen months of age, even with prolonged treatment. Prolonged immobilisation of the hip in this latter age group is usually accompanied by considerable joint stiffness, contracture, atrophy of muscles and osteoporosis; furthermore, immobilisation provides little stimulus for osseous development of the acetabulum (Hass 1951). The type of retention that allows movement of the hip within a restricted range provides a better stimulus for osseous development of the acetabulum than does immobilisation (Ponseti 1944, Schwartz 1945, Compere and Schnute 1946), but even this is often inadequate in the older child. The author suspects that retention of reduction by maintaining the hip in full medial rotation for several months or more actually produces medial femoral torsion which, in effect, amounts to increasing the degree of anteversion of the femoral neck.*

The percentage of unsatisfactory results from prolonged immobilisation of the reduced hip in children over the age of eighteen months has stimulated many orthopaedic surgeons to adopt a more direct approach to the problem (Galloway 1920, Groves 1928, Farrell and Howorth 1935, Crego and Schwartzmann 1948, Somerville 1953, Somerville and Scott 1957, Trevor 1957).

Operations on the femur. Lateral rotation osteotomy-The role of femoral anteversion in congenital dislocation or subluxation of the hip is controversial (Badgley 1949, Hass 1951). The author agrees with Shands and Steele (1958) that if concentric reduction can be maintained while the child is walking, anteversion usually corrects spontaneously in time. Although lateral rotation osteotomy as advocated by Crego and Schwartzmann (1948), Platou (1953a), Somerville (1953) and Trevor (1958) is effective in directing the femoral head into the acetabulum and preventing anterior subluxation, it does not always prevent upward and lateral subluxation because it does not ensure satisfactory coverage of the femoral head. Furthermore, if the hip has not been made stable by the rotation osteotomy the anteversion recurs, necessitating a second rotation osteotomy.

Adduction osteotomy-Valgus deformity of the femoral neck in these patients is often more apparent than real because of anteversion of the femoral neck. Nevertheless true valgus deformity does occur occasionally. In such a case subtrochanteric adduction osteotomy improves the stability of the hip by placing the femoral neck in abduction relative to the acetabulum (Pauwels 1951). This operation has the disadvantage of producing considerable shortening of the limb; furthermore, the ilium-to-trochanter distance is decreased and the efficiency of the abductor muscle group is thereby diminished. It is significant that often the surgically produced varus gradually straightens out over the ensuing few years, even to the extent of returning to a valgus deformity. Combined adduction and lateral rotation osteotomy has been performed by some surgeons (Somerville and Scott 1957, Trevor 1958) in an attempt to improve the result derived from lateral rotation osteotomy alone.

Operations on the pelvis-Various operative procedures have been performed on the pelvis to provide stability of the reduced congenital dislocation and congenital subluxation. Their

* This phenomenon is at present being investigated in growing rabbits.

vol. 43 B, NO. 3, AUGUST 1961

G 
terminology is somewhat confusing but they conform to three main types: the shelf operation, acetabuloplasty and capsular arthroplasty.

Shelf operation-In this paper the term shelf operation will mean the construction of an extra-articular bony buttress extending beyond the joint margin without alteration of the slope of the acetabulum (Gill 1935, Dickson 1935, Bosworth, Fielding, Liebler, Ishizuka, Ikeuchi and Cohen 1960). The buttress, if placed close to the joint margin and directed downward, laterally and parallel to the neck of the femur, reinforces the fibrous capsule of the joint and prevents lateral and upward subluxation. The osseous development of the acetabulum may or may not improve but the hip usually remains stable. Often the buttress is placed in an incorrect position; because it then serves no useful purpose it gradually disappears (Ponseti 1946). The type of bony buttress constructed over a completely dislocated femoral head is irrelevant to this discussion.

Chiari (1955) and Kawamura (1959) described another method of providing an extraarticular bony buttress. After complete osteotomy of the pelvis above the acetabulum, the distal segment containing the hip joint is shifted medially. The cut surface of the proximal segment then lies directly above the medially displaced femoral head, thereby preventing subsequent upward subluxation. The main source of concern about this operation is the resultant decrease in the capacity of the bony pelvis which, in females, could well present obstetrical difficulties in adult life. The author has had no experience with this procedure.

Acetabuloplasty-An operation designed to change the slope of the roof of the acetabulum by an incomplete osteotomy above the joint and insertion of a bone graft to keep the osteotomy site open, will be referred to in this paper as acetabuloplasty (Albee 1915, Crego and Schwartzmann 1948, Wiberg 1953). In $1934 \mathrm{McD}$ onald, in an attempt to obtain better coverage of the femoral head, began to perform an extensive type of acetabuloplasty which he called "depression of the roof of the acetabulum"; the osteotomy extended inwards to, and occasionally through, the inner cortex of the ilium and the depression of the acetabular roof was maintained by beef bone wedges. Pemberton (1958), recognising the importance of preventing redislocation anteriorly, devised a more extensive type of acetabuloplasty which he called osteotomy of the ilium with rotation of the acetabular roof. The osteotomy extends through the inner cortex of the ilium but not into the sciatic notch, and the iliac portion of the acetabulum is hinged forward on the triradiate cartilage.

Line drawings of the various types of acetabuloplasty tend to be misleading because they usually show a perfectly smooth contour of the acetabulum after operation; but, as can be readily demonstrated in the cadaver, it is not possible to change the slope of only the iliac part of the socket without producing an angulation of the articular surface and a triangular shape of the rim of the acetabulum. Because of this, the internal congruity of the joint is altered and degenerative changes in the joint may be expected later. Also, it can be shown that the capacity of the acetabulum is decreased by acetabuloplasty; prising the acetabular roof down against the femoral head produces excessive and continuous compression of the opposing joint surfaces during the post-operative period of immobilisation and may result in pressure necrosis of articular cartilage (Salter and Field 1960).

Capsular arthroplasty - Colonna $(1936,1953)$ provided stability of reduction by creating a deep bony socket either at the site of the original acetabulum or slightly higher, and employed the redundant joint capsule as an interposition membrane on the principle of an arthroplasty. This procedure seems best suited for older children in whom it has not been possible to reduce the femoral head with impunity into the original acetabulum even after prolonged skeletal traction.

\section{RESLLTS OF EXISTING METHODS OF TREATMENT}

It is well recognised that many excellent results have been obtained in children over the age of eighteen months with previously untreated congenital dislocation and subluxation of the hip by one or more of the aforementioned methods of treatment. Nevertheless, in 

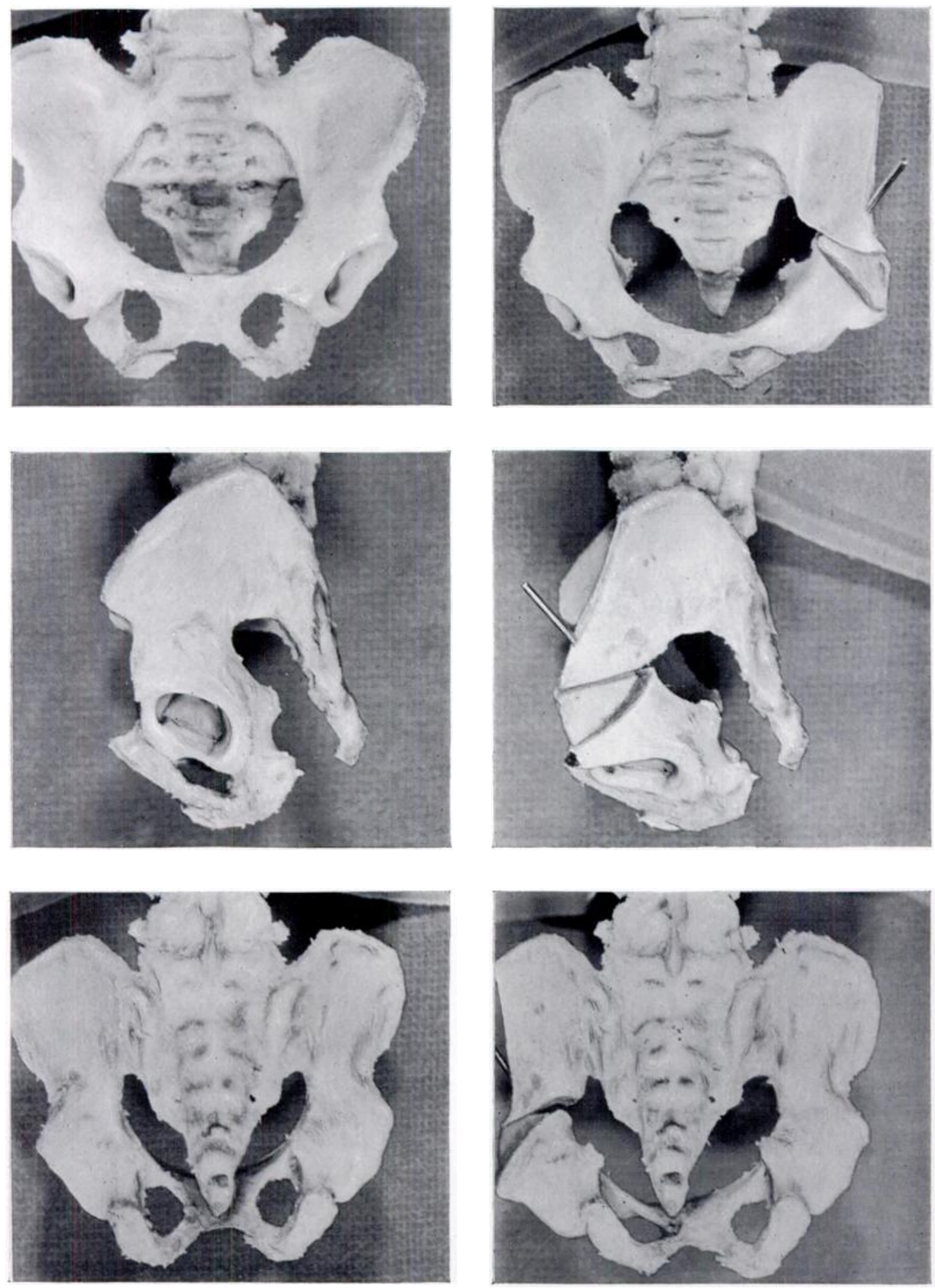

Fig. 1

Fig. 2

Dissected pelvis of a two and a half-year-old girl. Figure 1-Natural state. Figure 2-An osteotomy through the left innominate bone has been done to demonstrate the redirection of the entire acetabulum. 
the many well documented follow-up studies published the percentage of excellent results is not so high that the search for more effective methods of treating this difficult condition should cease (Gill 1948, Crego and Schwartzmann 1948, Leveuf 1948, Massie and Howorth 1951, Hass 1951, Muller and Seddon 1953, Platou 1953b, Platt 1956, Trevor 1957, Ponseti and Frigerio 1959, Esteve 1960, Wilkinson and Carter 1960, MacKenzie, Seddon and Trevor 1960).

THE BASIC CAUSE OF INSTABILITY AFTER REDUCTION

Dissatisfaction with the results of existing methods of treatment in the child over the age of eighteen months has stimulated the author to study the basic cause of instability after reduction. The direction in which the acetabulum faces in a congenitally dislocated hip merits consideration. Langenskiöld (1953) and Laurent (1953) described a "frontal inclination" of the acetabulum, which faces in a more anterior and a less lateral direction than normal.

Radiographs fail to provide a three-dimensional concept of the acetabulum. The usual antero-posterior and "frog" positions give two views of the femora but only one of the pelvis. Oblique views of the pelvis are useful but a lateral view of the acetabulum is unsatisfactory. Only at open operation can one obtain a three-dimensional concept of the abnormality of the acetabulum in congenital dislocation of the hip, and the author has repeatedly made the observation that there is much more than a defect in the roof of the acetabulum. Indeed, the entire acetabulum, rather than facing downwards, is directed antero-laterally more than is normal, so that the femoral head is inadequately covered anteriorly when the hip is extended and laterally when the hip is adducted. This observation explains why the reduced hip is stable in a position of abduction and flexion and why it redislocates or resubluxates laterally in a position of adduction and anteriorly in a position of extension. This observation also explains why, in the presence of excessive anteversion of the femur, the combination of lateral rotation and extension results in anterior redislocation or resubluxation. In the author's opinion the basic abnormality responsible for instability of the reduced congenital dislocation is the abnormal direction in which the entire acetabulum faces.

\section{THE DESIGN AND PRINCIPLE OF INNOMINATE OSTEOTOMY}

From the foregoing observations it seemed reasonable that if the entire acetabulum could be made to face in a normal direction the reduced hip would be stable in the position of function. Consequently, an operation has been designed to redirect the entire acetabulum as one piece. Studies on the cadaver revealed that if the innominate bone was completely divided transversely just above the hip joint the acetabulum, being contained in the distal segment, could be redirected in a satisfactory manner by opening the osteotomy site antero-laterally (Figs. 1 and 2). These studies also demonstrated conclusively that all three components of the acetabulum (ilium, pubis and ischium) remained as a unit and that the distal segment of the innominate bone definitely changed direction by a combination of hinging and rotation through the symphysis pubis which, in children, is quite mobile. It was also possible to demonstrate that innominate osteotomy produced neither an alteration in the shape of the acetabulum nor a decrease in its capacity (Fig. 3).

The principle of innominate osteotomy is simply redirection of the entire acetabulum in such a way that the reduced dislocation or subluxation, which previously was stable only in a position of abduction and flexion, is made stable in the position of function (Fig. 4). This allows early weight bearing which, with the stability, is an excellent stimulus for further osseous development of the components of the hip.

\section{APPLICATION OF THE PRINCIPLE OF INNOMINATE OSTEOTOMY}

The principle of innominate osteotomy is equally applicable to both congenital dislocation and congenital subluxation in the age group under consideration. Complete reduction of the 
hip is an essential prerequisite for innominate osteotomy. In order to achieve absolute concentric reduction of a complete dislocation in this age group it is often necessary to open the joint at the time of operation; complete reduction of a subluxation is obtained by abducting and flexing the hip.

Congenital dislocation. Preliminary traction - In a child over the age of eighteen months with congenital dislocation of the hip the pelvifemoral muscles, particularly the iliopsoas, the adductors and the hamstrings, have failed to lengthen adequately. Therefore, continuous skin traction is employed before any attempt at reduction is made. The period of traction varies with the age of the child and the amount of displacement, but the average is about two weeks. Attempt at closed reduction-Following the period of traction, any residual adduction

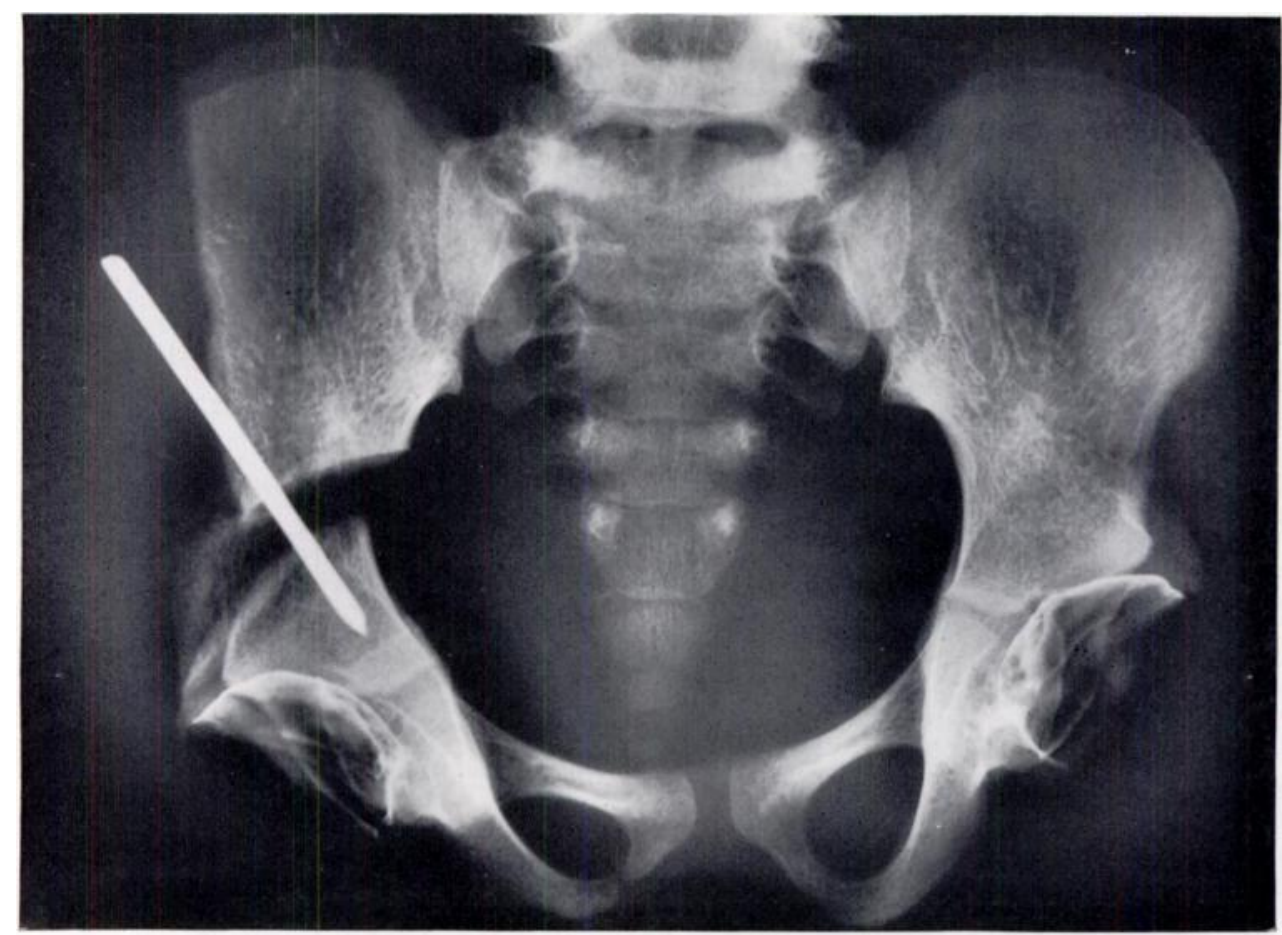

Fig. 3

Radiograph of the dissected pelvis of a two and a half-year-old girl. An innominate osteotomy has been done on the right. The acetabula have been lined with barium sulphate to show that the osteotomy has produced neither an alteration in the shape of the acetabulum nor a decrease in its capacity.

contracture is overcome by subcutaneous adductor tenotomy under general anaesthesia and a gentle attempt at closed reduction is made. Arthrography is helpful at this stage in assessing the completeness of reduction. If complete reduction can be obtained without the use of force, and if the reduction is reasonably stable in a moderate degree of abduction and flexion, a plaster hip spica is applied and operation is deferred. Should subsequent osseous development of the hip be inadequate, innominate osteotomy can be performed later. In the age group under consideration complete stable reduction is not usually obtained by the closed method, and open operation is required.

Congenital subluxation of the hip-The operative treatment of congenital subluxation of the hip is exactly the same as for congenital dislocation except that the joint need not be opened. Bilateral congenital dislocation or subluxation of the hip-Bilateral involvement may consist of bilateral dislocation, bilateral subluxation, or dislocation of one hip and subluxation of the other. The second hip is operated upon about two weeks after the first; blood transfusion is more often deemed necessary during the second operation than during the first. 


\section{TECHNIQUE OF COMBINED OPEN REDUCTION AND INNOMINATE OSTEOTOMY}

The surgical approach is so designed that the combination of accurate open reduction and stabilisation of the reduction by innominate osteotomy can be performed through the same incision at one operation. Blood transfusion is not always necessary, but continuous intravenous infusion is indicated as a precautionary measure should blood be required. The patient lies supine on the operation table with a sandbag under the thorax on the affected side (Fig. 5). The draping is so arranged that the lower limb is free to be moved during the operation. Any residual contracture of the adductor muscles is dealt with by subcutaneous adductor tenotomy unless it has been done earlier.

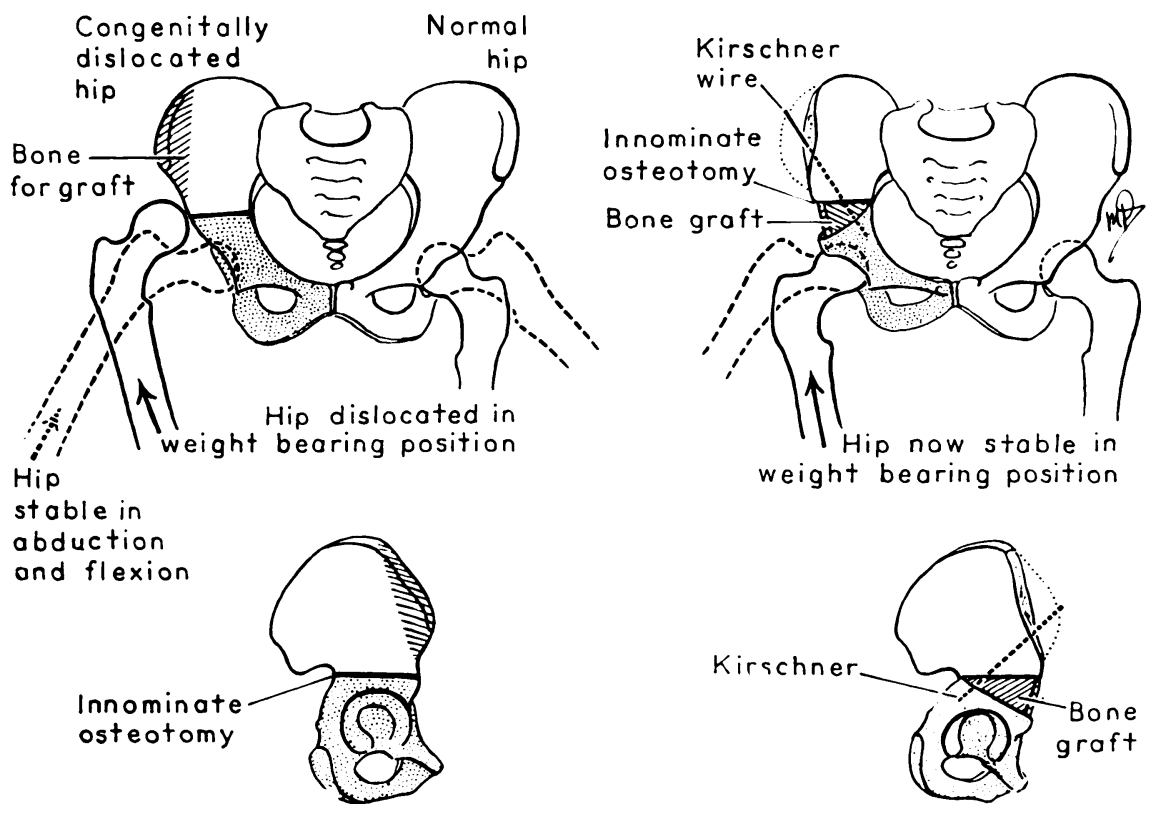

Fig. 4

The principle of innominate osteotomy.

Exposure-The skin incision begins below the middle of the iliac crest and passes obliquely forwards distal to the anterior superior spine almost to the mid point of the inguinal ligament (Fig. 5). The anterior aspect of the hip joint is exposed by dissecting between the tensor fasciae latae laterally and the sartorius and rectus femoris medially as described by SmithPetersen (1917), after which this space is packed (Fig. 6). An incision is made in the iliac apophysis down to bone along the iliac crest from its mid-point to the anterior superior spine and then distally to the anterior inferior spine. The lateral part of the apophysis with the periosteum of the external surface of the ilium is then stripped in a continuous sheet inferiorly to the lateral edge of the acetabulum and posteriorly to the greater sciatic notch: this space is then packed. If the fibrous capsule of the hip has become adherent to the lateral aspect of the ilium above the acetabulum by being stretched upward by the intracapsular dislocation it should be freed by the use of a periosteal elevator. Blunt dissection in the plane between the fibrous capsule and abductor muscles provides excellent exposure of the anterior and lateral part of the capsule (Fig. 7).

Open reduction-The capsule is opened widely close to the superior and anterior margins of the acetabulum (Fig. 8). Excessive fibro-fatty tissue in the base of the acetabulum is gently removed but the ligamentum teres is left intact unless it is grossly hypertrophied. The limbus does not obstruct reduction when the capsule is widely opened and therefore it is preserved. The abnormal direction in which the entire acetabulum faces can be appreciated at this stage. 
INNOMINATE OSTEOTOMY IN THE TREATMENT OF CONGENITAL DISLOCATION OF THE HIP 525

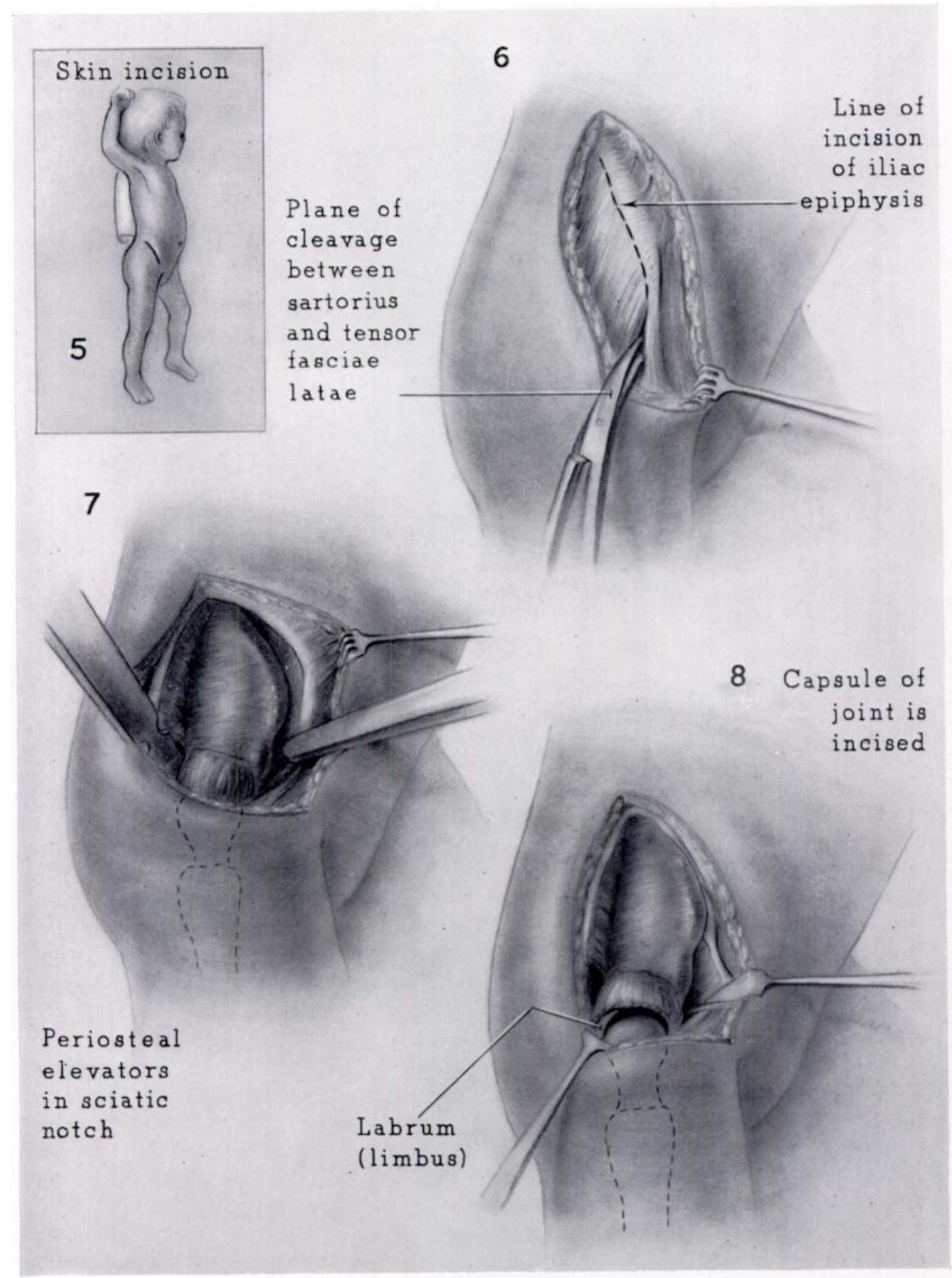

FIGS. 5 To 8

The technique of combined open reduction and innominate osteotomy.

VOL. 43 B, NO. 3, AUGUST 1961 


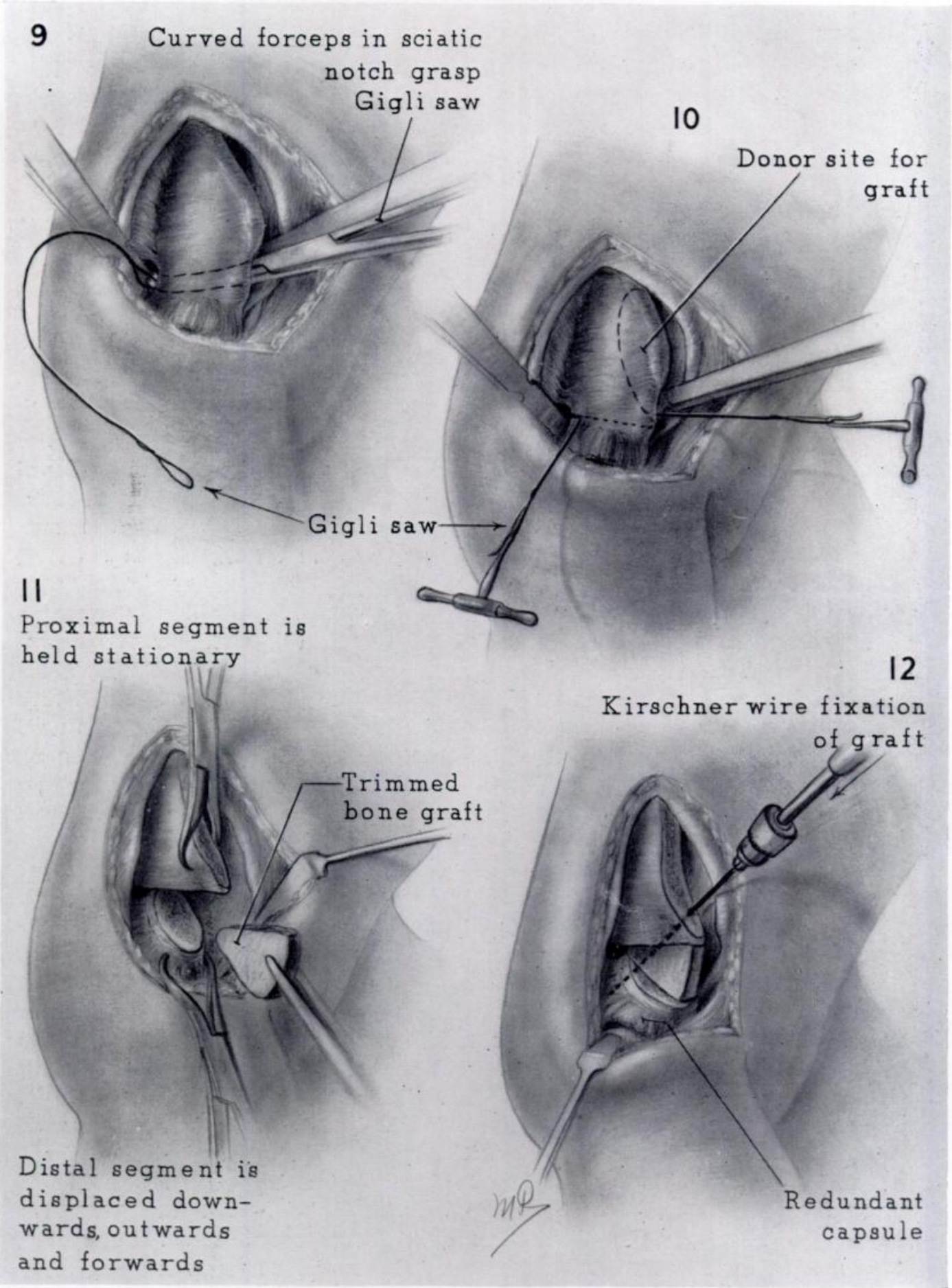

Figs. 9 To 12

The technique of combined open reduction and innominate osteotomy. 


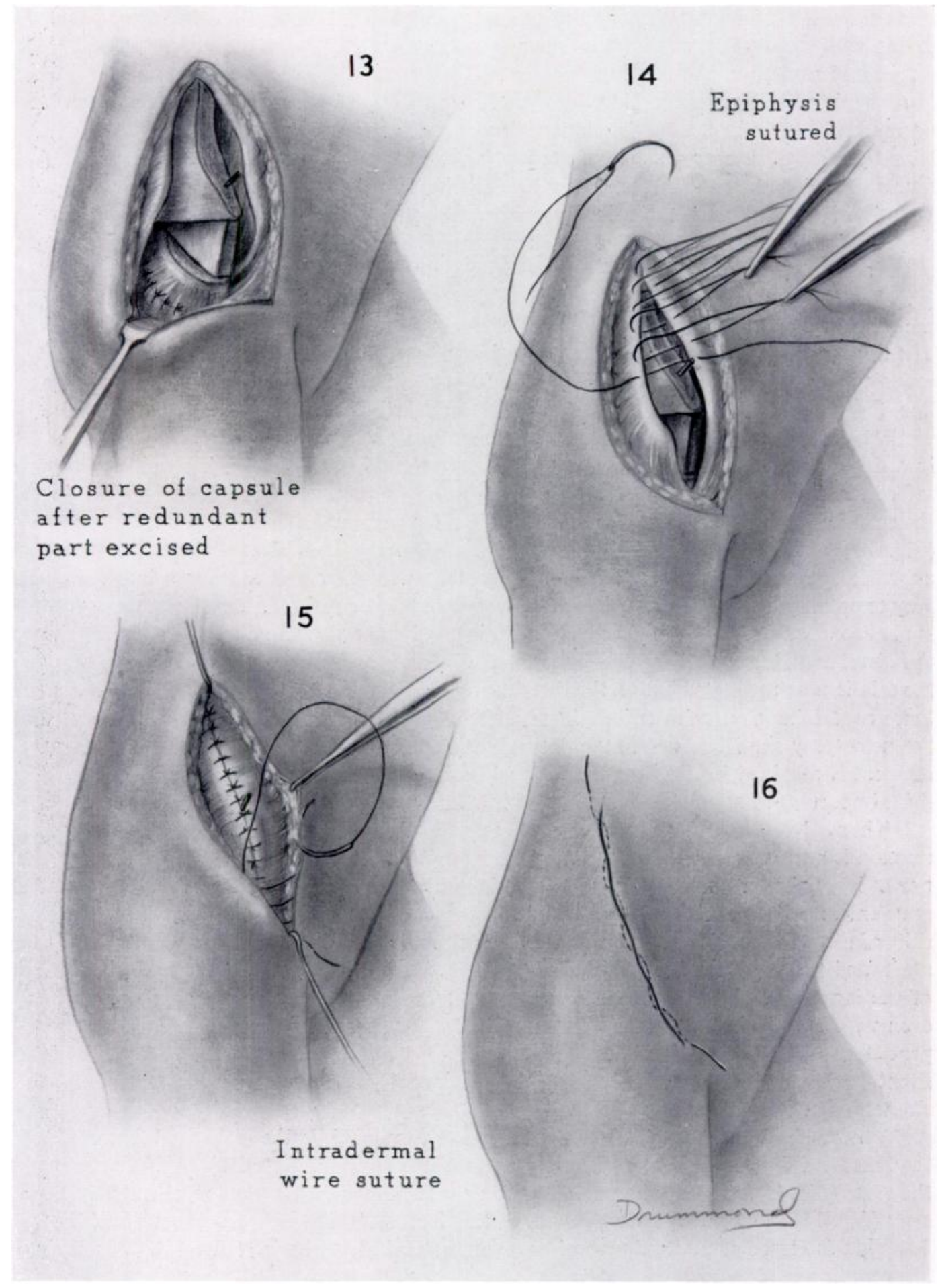

Figs. 13 To 16

The technique of combined open reduction and innominate osteotomy.

VOL. 43 B, NO. 3, AUGUST 1961 
The femoral head is gently reduced under direct vision. Particular attention is paid to the degree of shortening of the iliopsoas muscle because a shortened iliopsoas not only renders reduction difficult but also limits abduction and medial rotation when the hip is reduced; under such circumstances the tendinous part of the iliopsoas should be divided. The stability of reduction is assessed at this time. The reduction is found to be stable with the hip in abduction, flexion and varying degrees of medial rotation; however, redislocation usually occurs laterally when the hip is adducted and anteriorly when the hip is either extended or laterally rotated. Under such circumstances innominate osteotomy is carried out.

Innominate osteotomy-The outer surface of the ilium having been previously exposed, attention is now directed to its inner surface. The cartilaginous iliac apophysis is displaced medially from the anterior half of the iliac crest with an elevator, and the periosteum of the inner surface of the ilium is stripped off in a continuous sheet to expose the sciatic notch (Fig. 7). Care is taken to remain in the subperiosteal plane throughout, but particularly behind the sciatic notch because of the proximity of the sciatic nerve and the superior gluteal artery. The tip of a curved forceps is passed subperiosteally behind the notch from the medial side in order to grasp one end of the Gigli saw (Fig. 9). The osteotomy extends in a straight line from the sciatic notch to the anterior inferior spine and is at right angles to the vertical axis of the ilium (Fig. 10). The soft tissues are retracted medially and laterally in order that the bone may be easily divided with the Gigli saw, which is considered to be a safer instrument than an osteotome for this purpose. A generous full thickness bone graft is then removed from the anterior part of the iliac crest with large bone cutting forceps (Fig. 10), and is trimmed to the shape of a wedge, the base of which should correspond approximately to the distance between the anterior superior and inferior spines (Fig. 11). Any temptation to reduce the base of this wedge should be resisted. One stout towel forceps is used to steady the proximal segment of the innominate bone, and a second is used to grasp the distal segment posterior to the anterior inferior spine. By means of a curved elevator in the sciatic notch and traction on the distal towel forceps the distal segment of the innominate bone containing the entire acetabulum is shifted forwards, downwards and outwards so that the osteotomy site is opened antero-laterally (Fig. 11). The best displacement of the distal segment is obtained by allowing the femoral head to remain in the dislocated position. It is most important to avoid any backward or inward displacement of the distal segment.

The wedge-shaped bone graft is then inserted on its edge into the osteotomy site; when traction is released the graft is found to be held firmly by the two segments of the innominate bone. Nevertheless, a stout Kirschner wire is inserted across the osteotomy site, through the graft and into the distal segment posterior to the acetabulum in order to prevent any subsequent shift of the graft or of the distal segment (Fig. 12). At this point the femoral head is reduced again and the stability of reduction is reassessed. If the displacement of the distal segment of the innominate bone has been correct it will be found that the reduction is now stable even with the hip in the functional position of walking. Throughout the remainder of the procedure an assistant holds the lower extremity with the hip in a position of slight abduction, slight flexion and slight medial rotation. The knee is kept flexed to overcome the relative shortening of the hamstring muscles.

The residual pocket of joint capsule, formerly occupied by the dislocated femoral head, is obliterated by appropriate excision of redundant capsule followed by careful suturing of the edges (Fig. 13). The two halves of the iliac apophysis are then sutured together over the iliac crest (Fig. 14). The Kirschner wire is cut so that its end lies in the subcutaneous fat (Fig. 15). The skin is closed with continuous intradermal stainless steel wire (Fig. 16). A unilateral hip spica is applied with the hip still in the same position of slight abduction, slight flexion and slight medial rotation. The knee is maintained in a flexed position to diminish the tension of the relatively short hamstring muscles and thereby prevent continuous compression of the articular cartilage of the hip joint during the period of immobilisation. 
Throughout the operation bleeding is controlled by packing and coagulation. The amount of blood loss-measured by weighing sponges and recording suction volumes-varies from 100 to 200 millilitres and the time for the combined operation of open reduction and osteotomy is usually one hour.

Post-operative management-The hip spica is removed after six weeks and radiographs are taken. The Kirschner wire is removed under a general or local anaesthetic. Active movements are permitted, and as soon as muscle tone is satisfactory partial weight bearing with crutches is encouraged for a few weeks after which full weight bearing is allowed. In older children it is sometimes felt necessary to apply plaster boots with an abduction bar for a month before weight bearing is allowed.

\section{INDICATIONS FOR INNOMINATE OSTEOTOMY}

Although the main indication for innominate osteotomy is in the primary treatment of congenital dislocation of the hip in children aged eighteen months to six years, and of congenital subluxation up to early adult life, it is also indicated as a secondary treatment for residual or recurrent dislocation or subluxation after other methods of treatment.

Other conditions that can be treated by this method are paralytic dislocation or subluxation - whether from poliomyelitis, spina bifida or cerebral palsy; residual pathological dislocation or subluxation after septic arthritis; and subluxation of the hip secondary to a fixed pelvic obliquity such as occurs with an uncorrectable lumbar scoliosis.

\section{CLINICAL MATERIAL}

At the time of writing ninety-six innominate osteotomies have been done at the Hospital for Sick Children, Toronto, since November 1957. Of these, fifty-eight were done as the primary treatment in forty-one children. More than twice this number of children, mostly under the age of eighteen months, were treated conservatively during the same period.

The clinical material in this series consists of twenty-five congenitally abnormal hip joints in eighteen children aged eighteen months to six years at the time of initial treatment, the average being thirty-three months. They were all consecutive patients and the first innominate osteotomy was performed in November 1957. There were nineteen congenital dislocations and six congenital subluxations. The aforementioned regimen was the initial-and only-method of treatment used. The children were followed at regular intervals after operation; the follow-up period was taken from the time the child started to walk after the operation. The shortest follow-up was one year and the longest three years.

\section{RESULTS}

Clinical assessment of the early results of any method of treatment of congenital dislocation or subluxation of the hip in children tends to be misleading because the clinical result one or two years after treatment may be very satisfactory even in the presence of imperfect correction of the anatomical abnormality of the hip. It is well recognised, however, that unless the anatomical abnormality has been well corrected the clinical result gradually deteriorates.

Clinical assessment in the present group of patients included the range of hip movement, stability, the Trendelenburg test and gait. The results at the time of follow-up were excellent in twenty-four of the twenty-five hips.

Anatomical results-Radiographic assessment of the anatomical result is more significant than clinical assessment of joint function, particularly in respect of prognosis. Indeed, Putti (1933) said that " no complete or permanent restoration of function occurs without a perfect anatomical restoration."

The anatomical results have been assessed by the method of Severin (1941) using the CE (centre-edge) angle devised by Wiberg (1939).

vol. 43 B, No. 3, AUgust 1961 


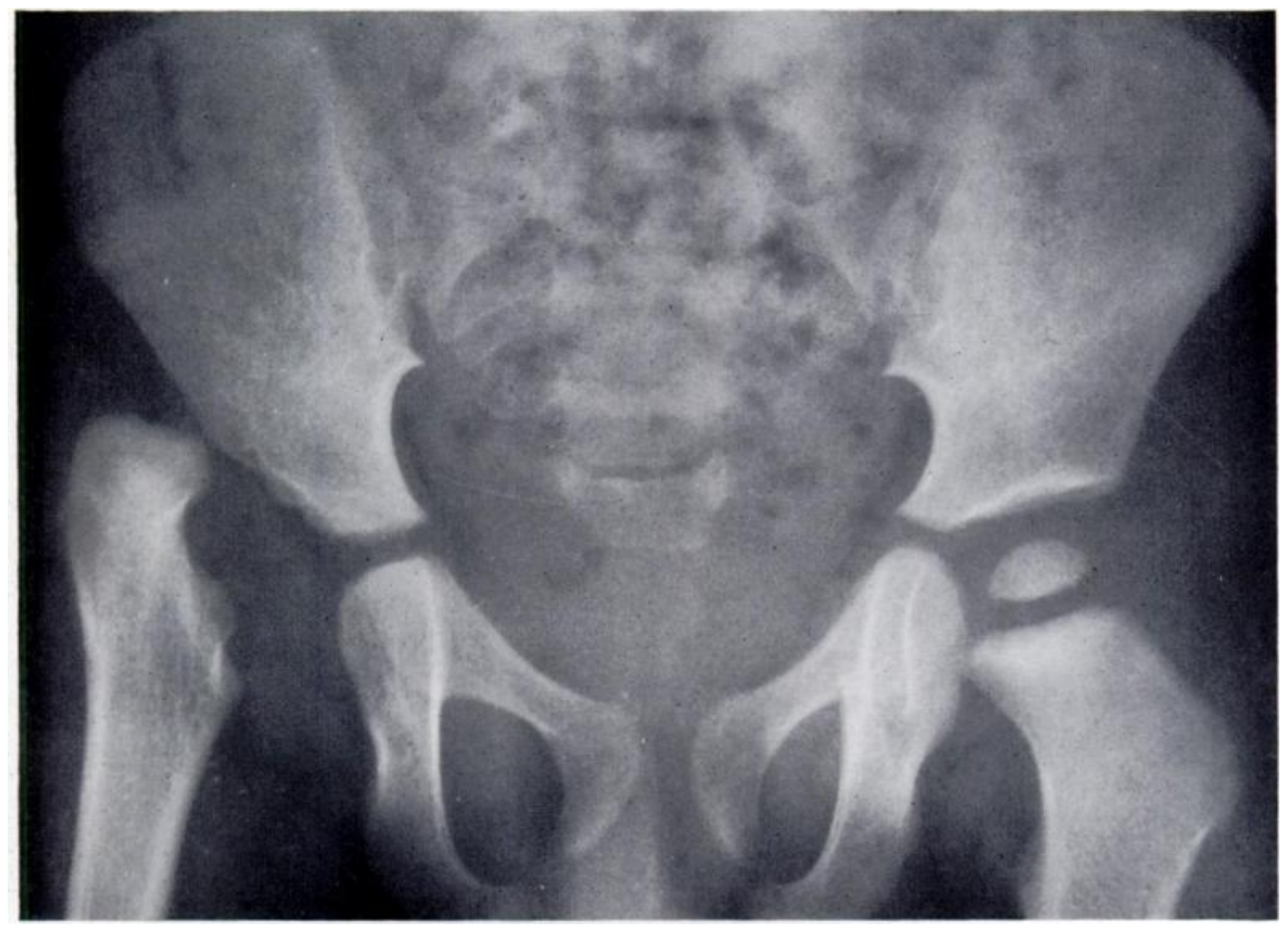

FIG. 17

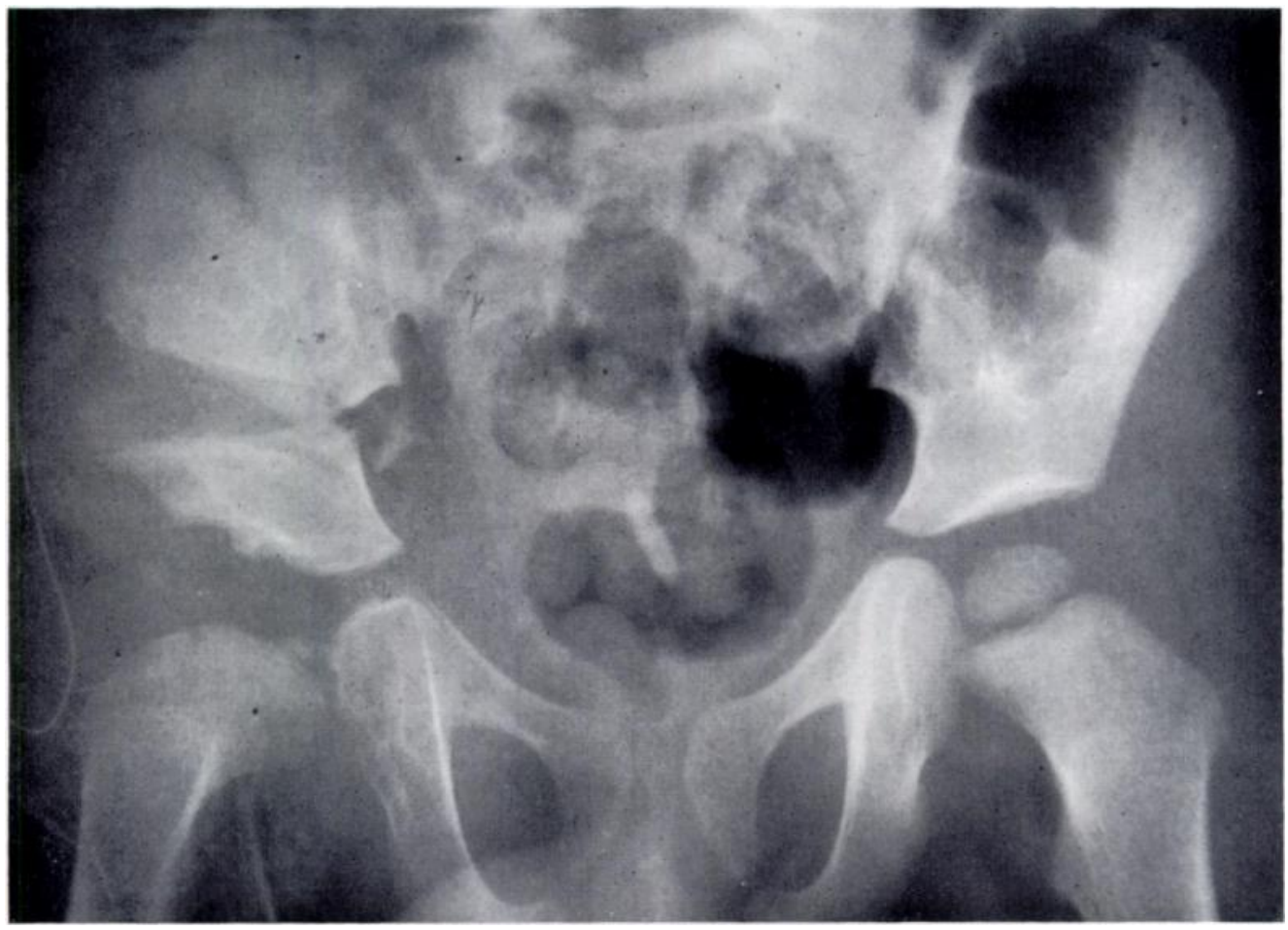

FIG. 18

Case 1-A two-ycar-old boy with previously untreated congenital dislocation of the right hip. Figure 17Before operation. Figure 18-At the time of open reduction and innominate osteotomy of the right hip. 


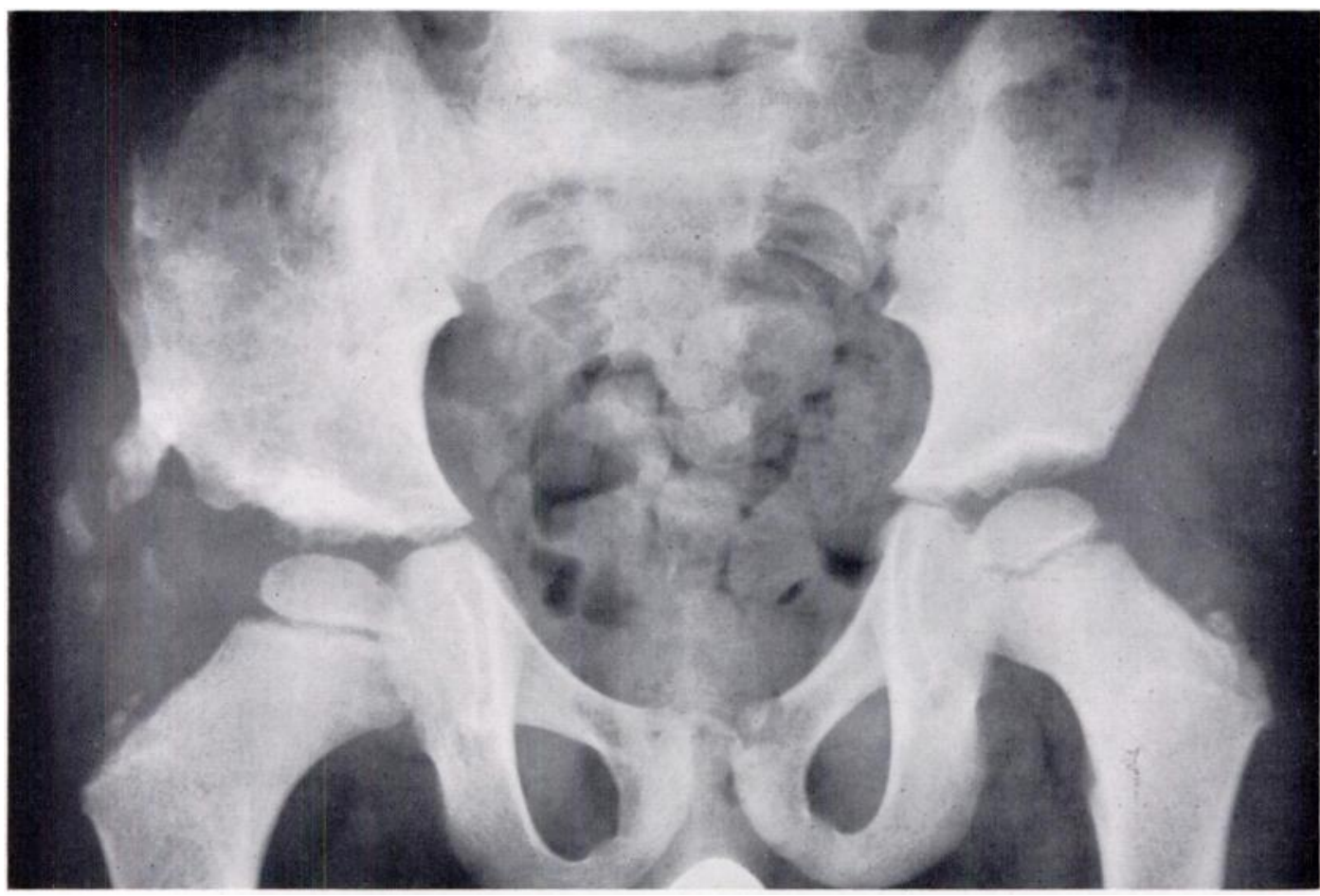

Fig. 19

Case 1-Two and three-quarter years after open reduction and innominate osteotomy.

Type I-The hip is perfect in all respects, with rounded head and normal neck and acetabulum: $a$ ) the $\mathrm{CE}$ angle is more than 19 degrees between the ages of six and thirteen; $b$ ) the $\mathrm{CE}$ angle is from 15 to 19 degrees between the ages of six and thirteen.

Type II-One or both of the head and neck of the femur reveal moderate deformity, the shape of the acetabulum is good and there is no subluxation: $a$ ) the CE angle is the same as in Type Ia $; b$ ) the CE angle is the same as in Type Ib.

Type III-There is dysplasia of the acetabulum but no subluxation of the joint. The CE angle is less than 15 degrees in ages from six to thirteen years.

Type IV-The femoral head is subluxated and articulates with a shallow acetabulum: $a$ ) positive $\mathrm{CE}$ angle, or equal to zero; $b$ ) the $\mathrm{CE}$ angle is negative because the subluxation is greater.

Type $V$-The femoral head articulates with a "secondary acetabulum" developed in the higher part or on the edge of the true acetabulum. In this type, as in Type IV, there is often considerable deformity of the head and neck of the femur.

Type $V I$-There is a complete dislocation.

This seems to be the most critical method of assessing both maintenance of complete reduction and osseous development of the acetabulum and femoral head.

The anatomical results are shown in Table I. It will be seen that all of the twenty-five hips may be considered excellent or good; there have been no poor results and no failures in this group of patients. The two Type III results were in the two hips of a girl aged five and a half at the time of treatment. Radiographs of six treated hips in four patients are shown in Figures 17 to 28 to demonstrate that the correction of the abnormal direction of the acetabulum has been maintained and there has been no evidence of growth disturbance of the pelvis. The donor site of the bone graft has filled in with new bone restoring the contour of the crest of the ilium. 
Complications-There were no operative complications. One patient developed a superficial post-operative wound infection which subsided rapidly. Avascular necrosis of the femoral head occurred in one of the twenty-five hips. One child fell from a chair three months after operation and the hip redislocated; reduction was possible and the hip has remained stable since.

TABLE I

Anatomical Results in Twenty-five Hips Treated by Innominate Osteotomy Assessed by THE Method OF Severin (1941)

\begin{tabular}{|c|c|c|c|c|c|c|c|c|c|c|c|}
\hline & & \multirow{2}{*}{$\begin{array}{c}\text { Number } \\
\text { of } \\
\text { hips }\end{array}$} & \multicolumn{2}{|c|}{ Excellent } & \multicolumn{3}{|c|}{ Good } & \multicolumn{2}{|c|}{ Fair } & \multicolumn{2}{|c|}{ Failures } \\
\hline & & & Ia & Ib & IIa & IIb & III & IVa & IVb & $\mathbf{v}$ & VI \\
\hline Dislocation & . & 19 & 15 & 1 & 2 & - & 1 & - & - & - & - \\
\hline Subluxation & . & 6 & 3 & 1 & 1 & - & 1 & - & - & - & - \\
\hline Total & . & 25 & 18 & 2 & 3 & - & 2 & - & - & - & 一 \\
\hline \multicolumn{3}{|c|}{ Per cent of total } & \multicolumn{2}{|c|}{80} & \multicolumn{3}{|c|}{20} & \multicolumn{2}{|c|}{-} & \multicolumn{2}{|c|}{-} \\
\hline
\end{tabular}

\section{DISCUSSION}

Galen labelled the hip bone "os innominatum" (L., nameless bone) because its unique shape defied a concise descriptive term. Osteotomy through this bone involving a unique displacement presents a similar problem of etymology and therefore the author has designated the operation " innominate osteotomy."

Displacement of the osteotomy-Although innominate osteotomy is not a difficult procedure, the exact displacement of the distal segment as described above must be obtained with certainty in order that the underlying principle of the operation may be obeyed. The distal segment must not be allowed to displace posteriorly or medially because such displacement not only defeats the principle of the operation but also results in an undesirable decrease in the internal diameter of the pelvis.

The limbus-The role of the limbus in congenital dislocation of the hip is controversial and merits discussion (Somerville 1953, Platt 1956, Trevor 1957). The author believes that the limbus, or fibrocartilaginous labrum, is not actually turned in on itself, but rather that it has simply grown without restraint during the months or years that the femoral head has been dislocated; a similar phenomenon is seen in the overgrown fibro-fatty tissue, or pulvinar, in the base of the acetabulum. Wide exposure of the superior and anterior aspect of the hip joint permits reduction of the femoral head deep to the overgrown limbus, which then comes to lie external to the perimeter of the head, thereby adding both depth to the acetabulum and stability to the reduction. For these reasons the author believes that the fibrocartilaginous labrum, or limbus, should be preserved.

Valgus and anteversion of the femur-Both valgus and anteversion of the femur tend to militate against a stable reduction of the hip when the limb is in the functional position of walking. In the author's opinion both of these deformities are secondary to the dislocation or subluxation rather than primary, and usually correct spontaneously with subsequent use of the reduced hip provided the reduction remains stable. After innominate osteotomy the reduced hip is stable even in the presence of fairly marked valgus and anteversion, because the femoral head is better covered both laterally and anteriorly. Thus femoral osteotomy is obviated unless the femoral deformities are extreme. No femoral osteotomy was performed in the patients included in this report.

Secondary treatment-In many ways and for many reasons a congenitally dislocated hip that has been unsuccessfully treated presents a more difficult problem than one that has not 


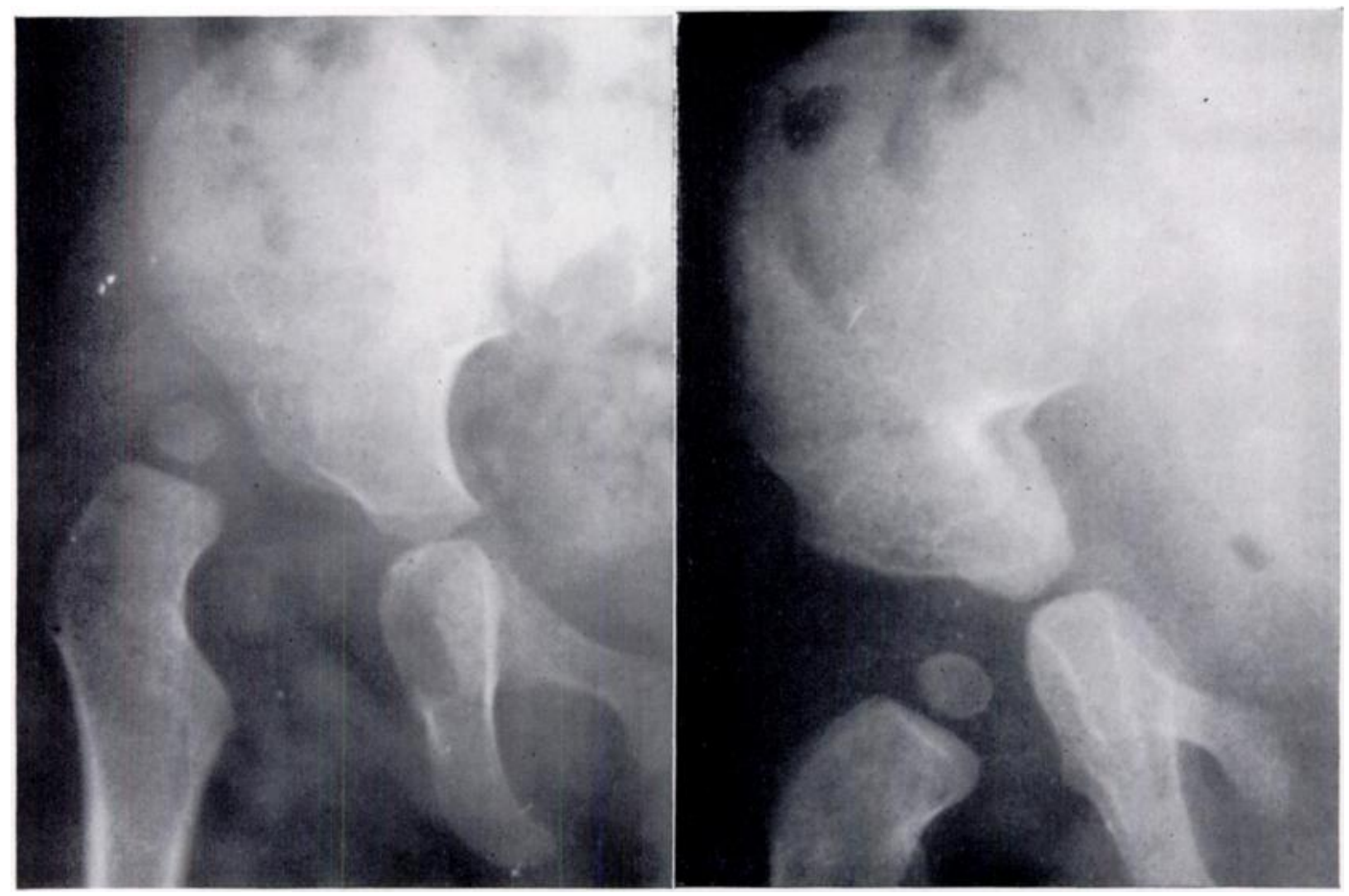

FiG. 20

Fig. 21

Case 2-A twenty-one-month-old girl with previously untreated congenital dislocation of the right hip. Figure 20-Before operation. Figure $21-$ Two and a half months after open reduction and innominate osteotomy.

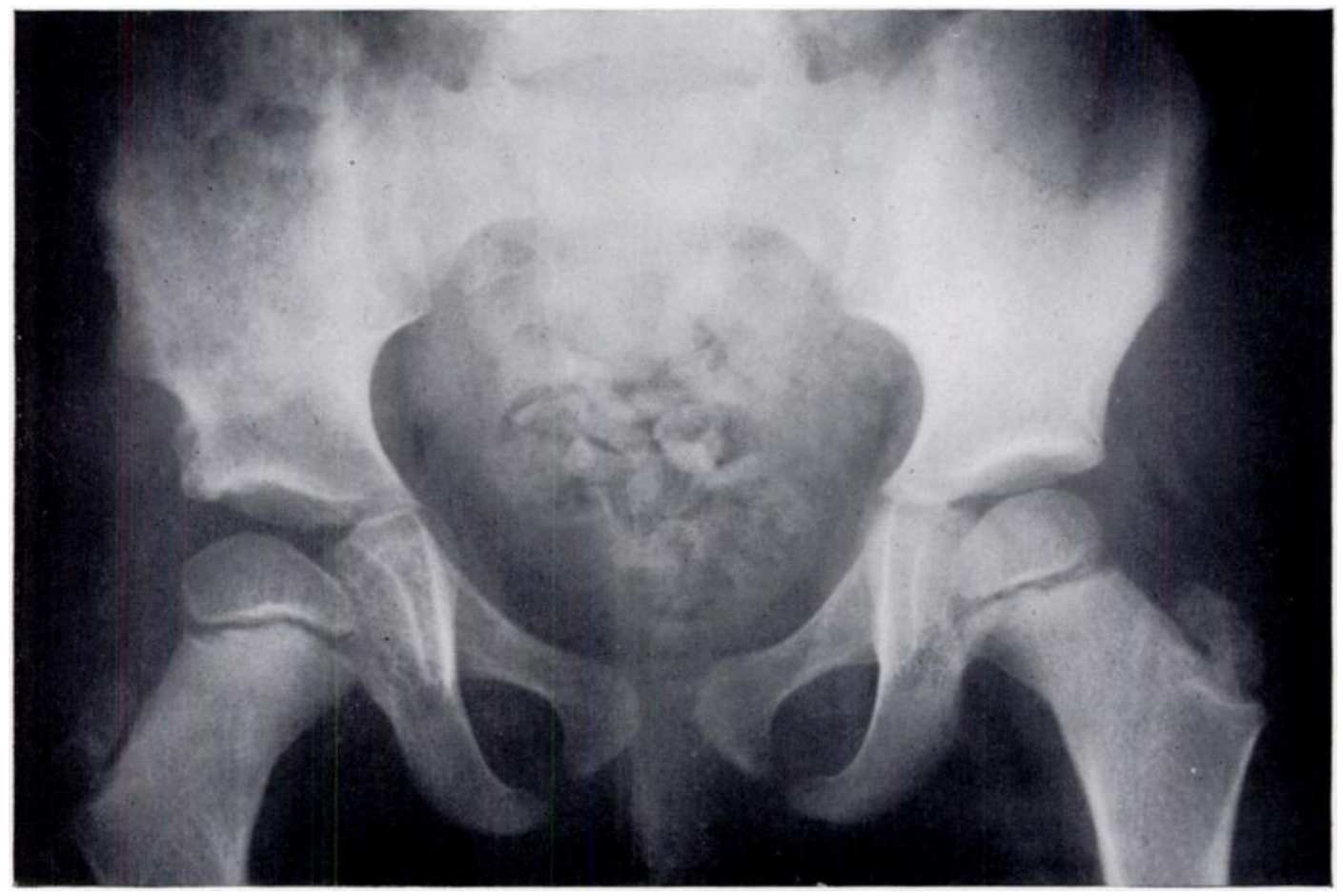

FIG. 22

Case 2-Two and a half years later.

vol. 43 B, NO. 3, AUGUST 1961 


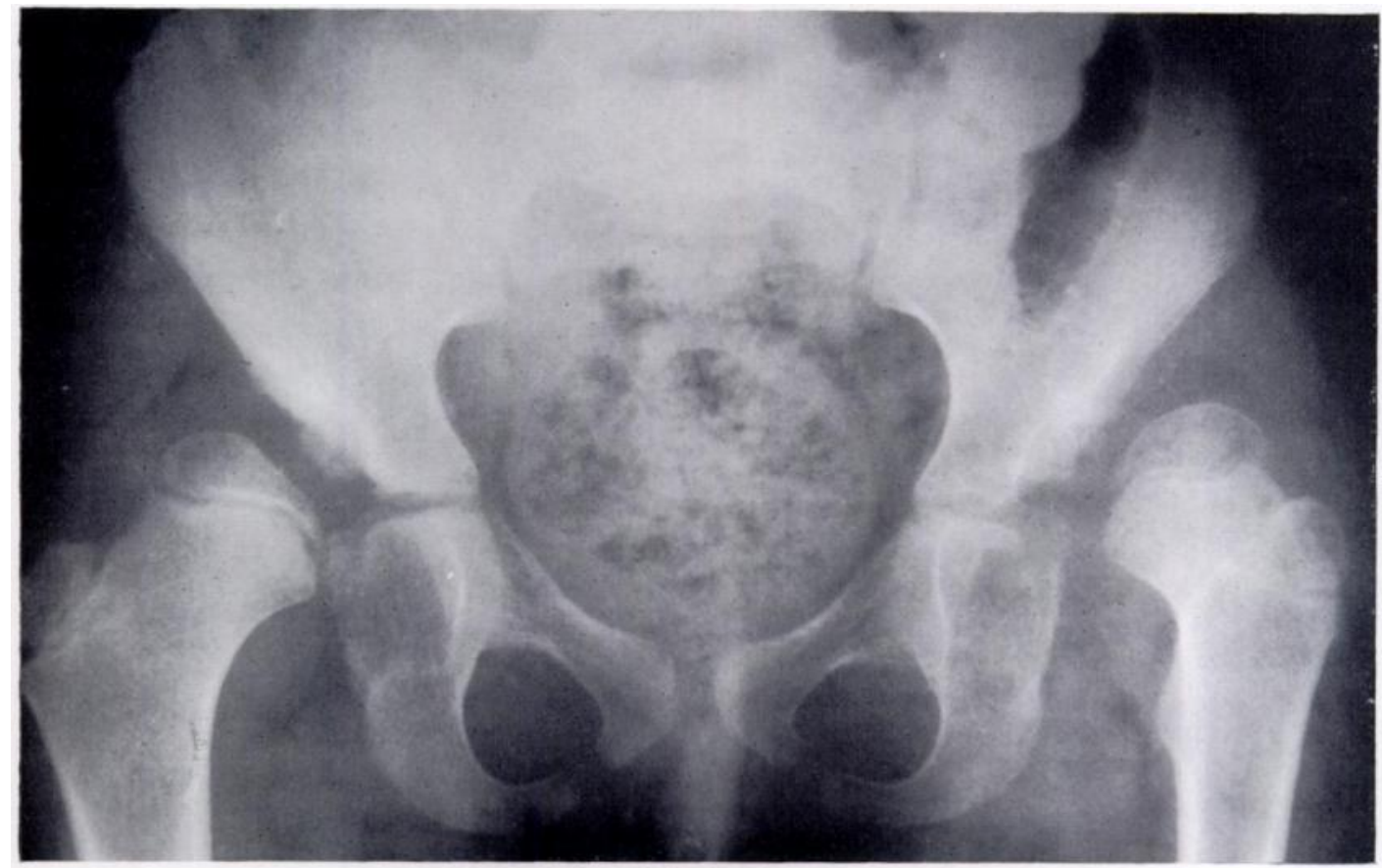

FIG. 23

Case 3-A five and a half-year-old girl with previously untreated congenital dislocation of the left hip and congenital subluxation of the right hip. Condition before operation.

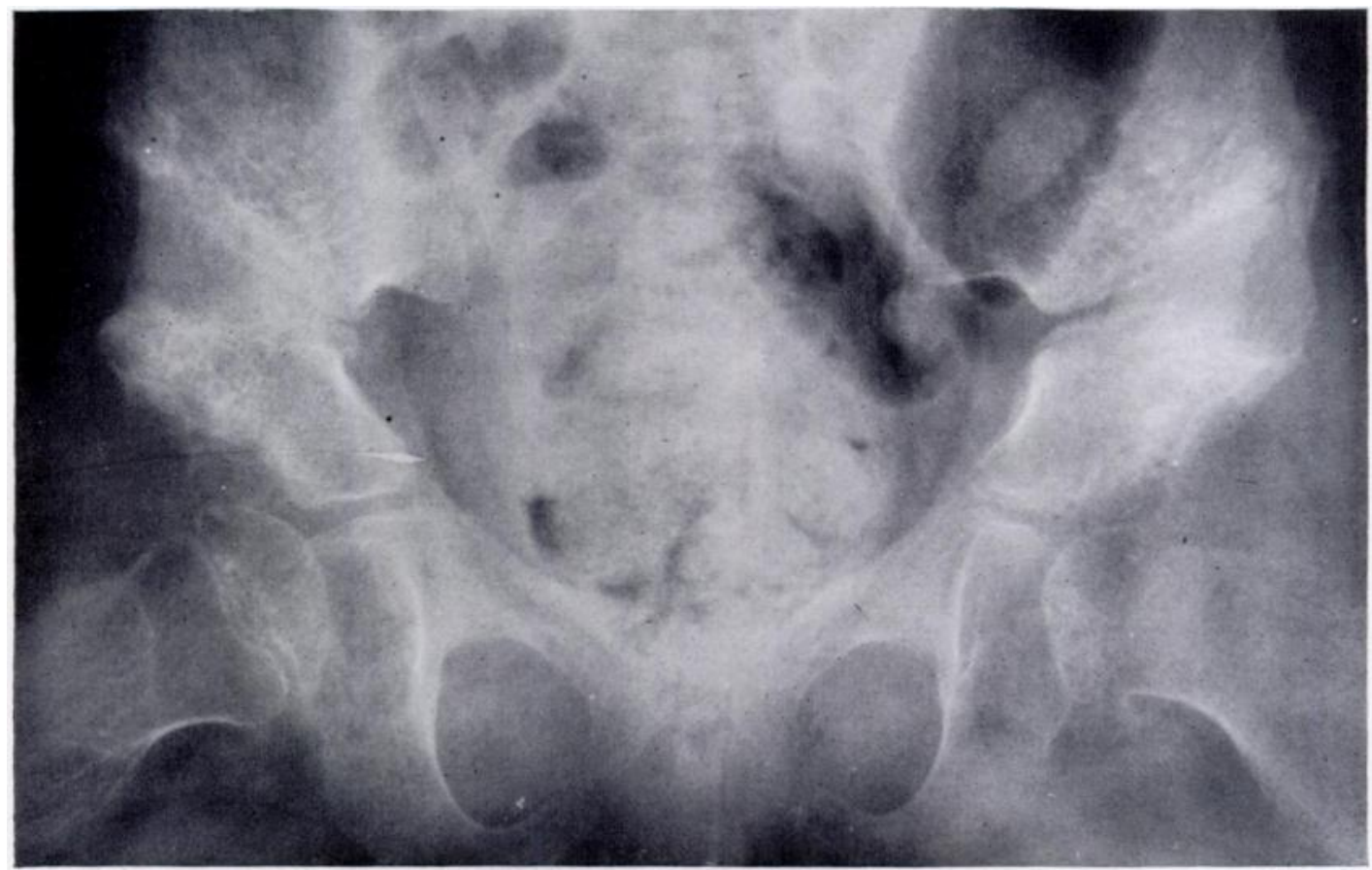

FIG. 24

Case 3-Two and a half months after innominate osteotomy of right hip and two months after open reduction and innominate osteotomy of left hip. 


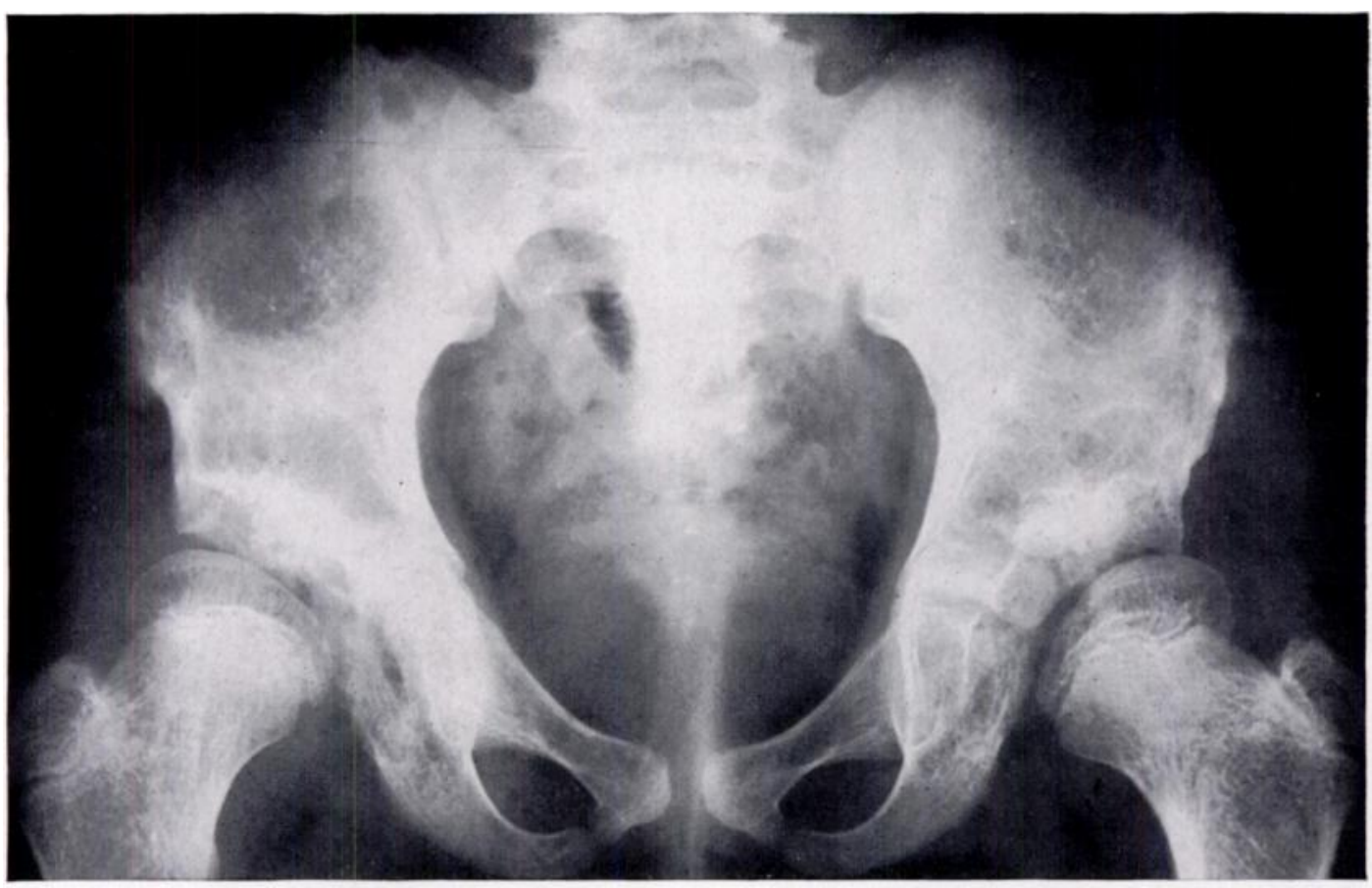

FIG. 25

Case 3-Two years after innominate osteotomy of right hip, and open reduction and innominate osteotomy of left hip; the result in both was graded Type III.

been previously treated. It should be pointed out that, on the whole, the results of innominate osteotomy in the secondary management of an unsuccessfully treated hip cannot be expected to be as satisfactory as the results of innominate osteotomy in primary treatment.

Shape and capacity of the acetabulum-The various types of acetabuloplasty, including the effective operation of Pemberton (1958), are based on the principle of altering only the iliac component of the acetabulum and therefore must both alter its shape and decrease its capacity. The author believes that the principle of preserving the shape and capacity of the acetabulum is important to the future function of the joint; only a comparison of the long-term results of acetabuloplasty and innominate osteotomy will determine the importance of this principle.

\section{ADVANTAGES OF INNOMINATE OSTEOTOMY}

Correction of the abnormal direction in which the entire acetabulum faces provides immediate stability of reduction in the functional position of weight bearing without altering the congruity of the acetabulum or decreasing its capacity.

After innominate osteotomy the area of articular cartilage of the femoral head and acetabulum in contact in the functional position of weight bearing is considerably increased because the femoral head is better covered by the acetabulum. As a result, pressure of weight bearing is distributed over a larger area of articular cartilage; it is suggested that this may be an important factor in helping to prevent degenerative changes in the articular cartilage with subsequent function of the joint.

Both reduction and stability are provided by a single operative procedure; femoral osteotomy is obviated.

The stability of reduction permits early resumption of function of the hip, thereby avoiding the undesirable effects, as well as the hardships, of prolonged immobilisation.

vol. 43 B, No. 3, AUgUST 1961 


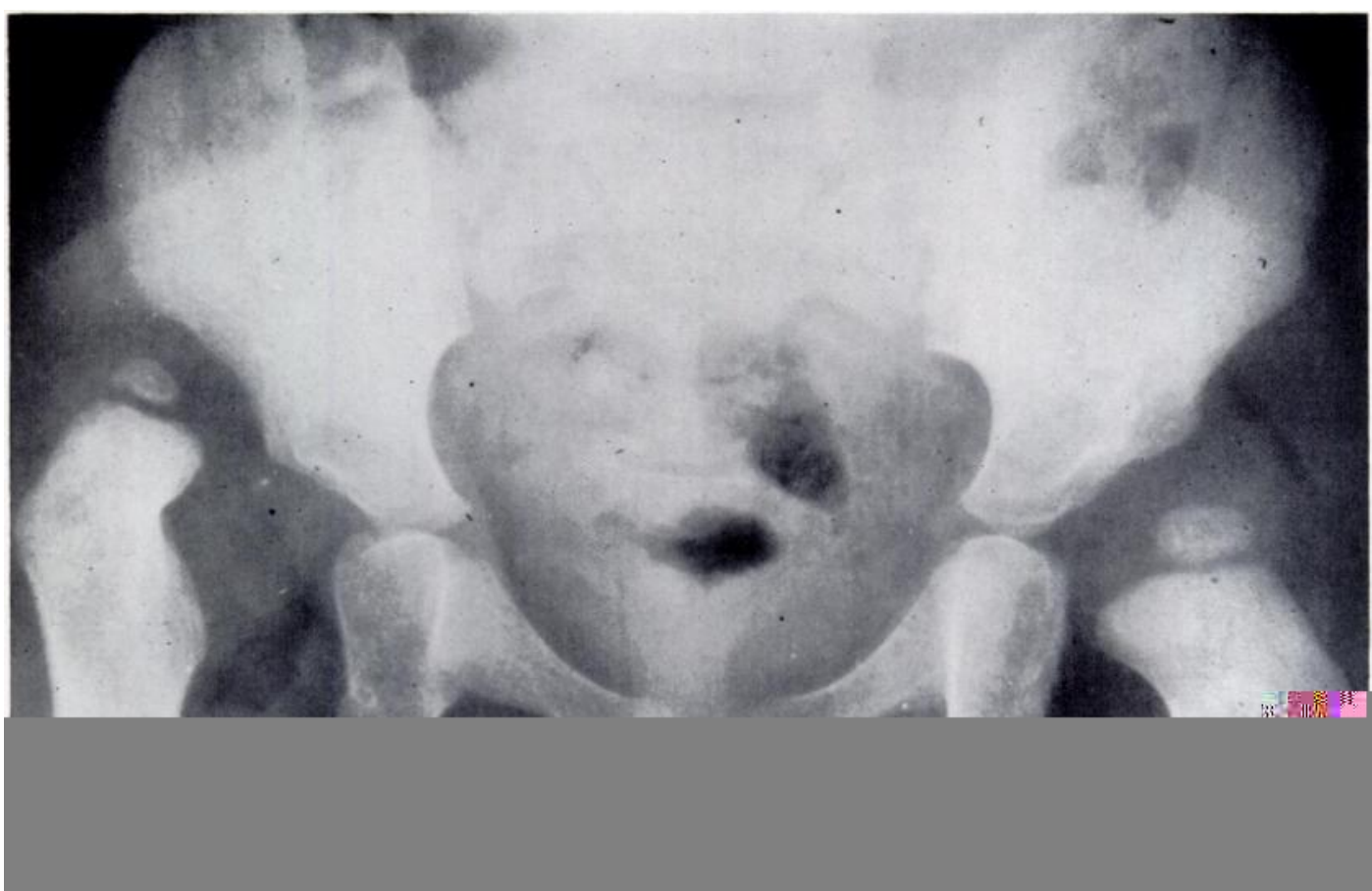

Fig. 26

Case 4-A two and a quarter-year-old girl with previously untreated congenital dislocation of the right hip and congenital subluxation of the left hip. Condition before operation.

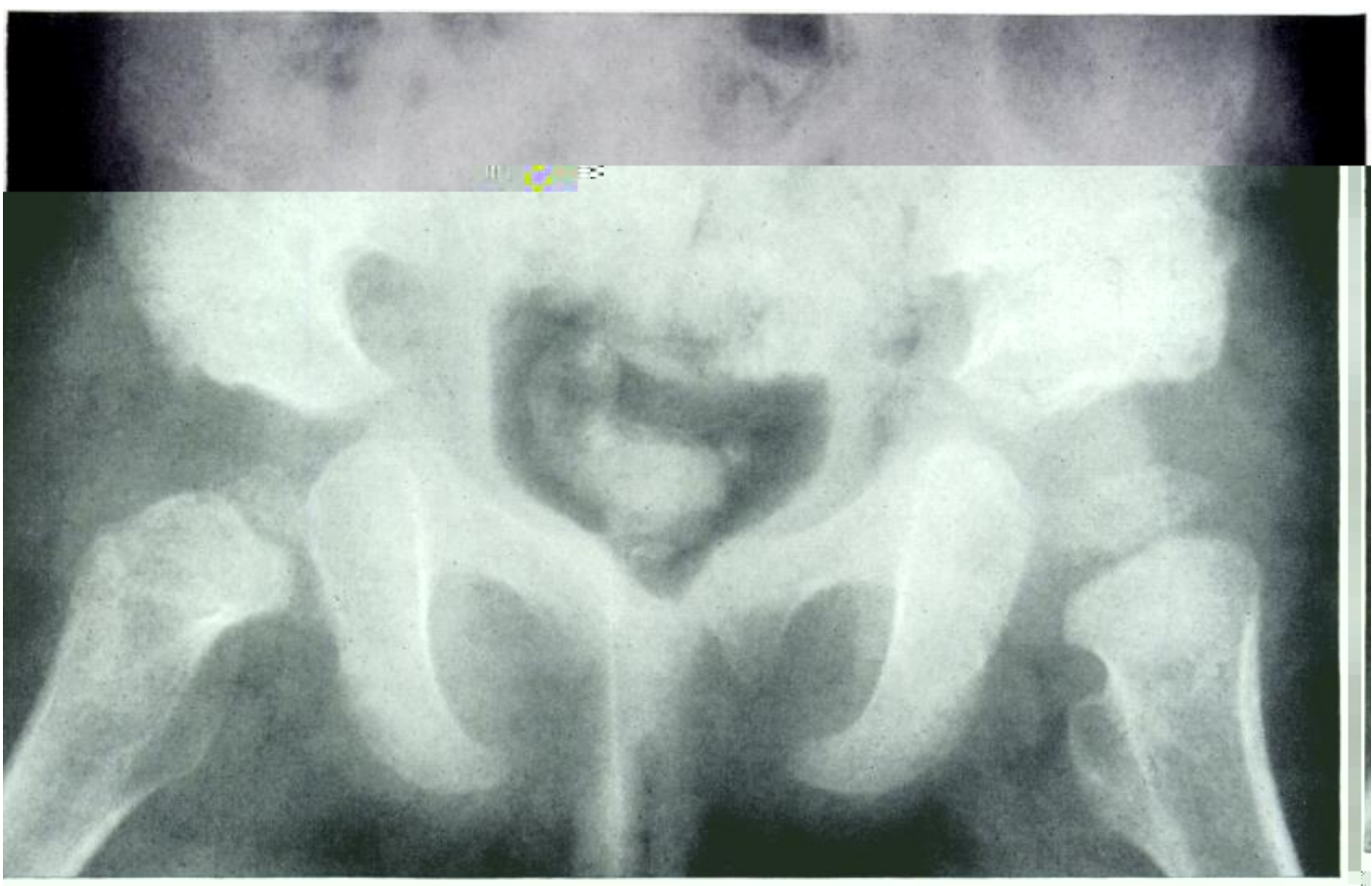

FIG. 27

Case 4-Two and a half months after open reduction and innominate osteotomy of the right hip and two months after innominate osteotomy of the left. 


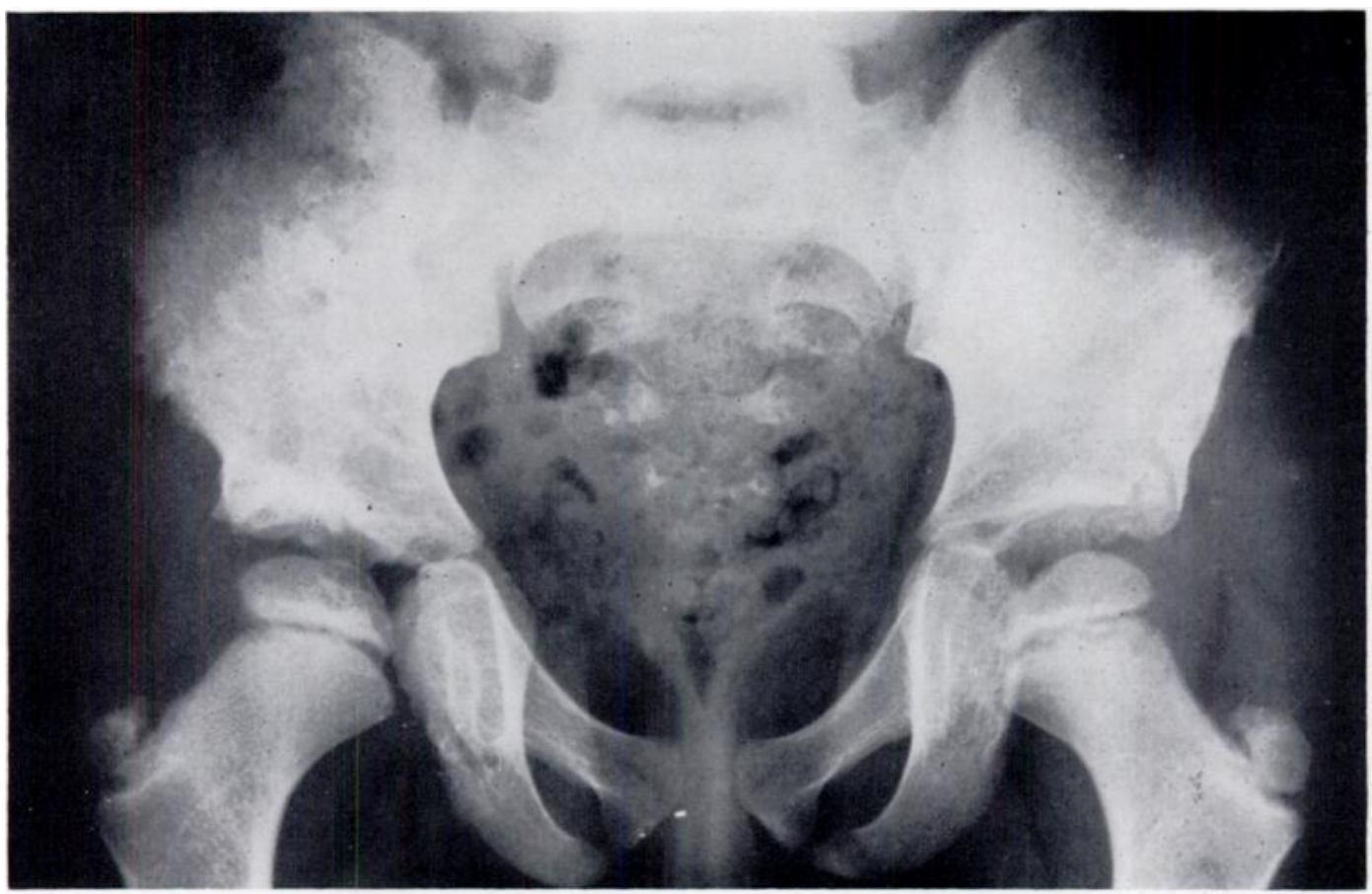

FIG. 28

Case 4-Two and three-quarters years after open reduction and innominate osteotomy of the right hip and innominate osteotomy of the left hip.

Early weight bearing on a completely reduced and completely stable hip seems likely to provide the best possible stimulus for subsequent normal development of both the femoral head and the acetabulum.

Many years must pass before the efficacy of innominate osteotomy can be assessed with any degree of certainty, but the early results are very encouraging. Early recognition is still, and will continue to be, the most important aspect of congenital dislocation and subluxation of the hip, and it is to be hoped that eventually all these children may be effectively treated by conservative means during the favourable first few months of life.

\section{SUMMARY AND CONCLUSIONS}

1. The problem of instability of reduction in congenital dislocation and congenital subluxation of the hip has been studied and it has been concluded that the basic cause of this instability is the abnormal direction in which the entire acetabulum faces.

2. An operation, innominate osteotomy, has been designed to correct the abnormal direction of the entire acetabulum in children over the age of eighteen months. The principle of innominate osteotomy is redirection of the acetabulum so that the reduced dislocation or subluxation, which previously was stable only in a position of abduction and flexion, is rendered stable in the functional position of weight bearing.

3. The operative technique, and the pre-operative and post-operative management are described.

4. The indications for innominate osteotomy are outlined and the advantages of the operation are enumerated.

5. The early results of innominate osteotomy are very encouraging.

The author wishes to express his gratitude to Miss Marguerite Drummond, medical artist, the Hospital for Sick Children, for the half-tone drawings of the operation, to her staff in the Department of Visual Education for the reproduction of radiographs, and to Dr O. R. McNeill for the photographs of the anatomical specimens.

vol. 43 B, No. 3, AUGUST 1961 


\section{REFERENCES}

Albee, F. H. (1915): The Bone Graft Wedge. Its Use in the Treatment of Relapsing, Acquired, and Congenital Dislocation of the Hip. New York Medical Journal, 102, 433.

BADGLey, C. E. (1949): Etiology of Congenital Dislocation of the Hip. Journal of Bone and Joint Surgery, 31-A, 341.

Bosworth, D. M., Fielding, J. W., Liebler, W. A., Ishizuka, T., IKeuchi, H., and Cohen, P. (1960): Hip Shelves in Children. Journal of Bone and Joint Surgery, 42-A, 1,223.

Chiari, K. (1955): Ergebnisse mit der Beckenosteotomie als Pfannendachplastik. (Results of pelvic osteotomy as of the shelf method of acetabular roof plastic.) Zeitschrift für Orthopädie und ihre Grenzgebiete, 87, 14.

Colonna, P. C. (1936): An Arthroplastic Operation for Congenital Dislocation of the Hip-a Two Stage Procedure. Surgery, Gynecology and Obstetrics, 63, 777.

Colonna, P. C. (1953): Capsular Arthroplasty for Congenital Dislocation of the Hip. Journal of Bone and Joint Surgery, 35-A, 179.

COMPERE, E. L., and SCHNUTE, W. J. (1946): Treatment of Congenital Dislocation of the Hip. Journal of Bone and Joint Surgery, 28, 555.

Crego, C. H., Jun., and Schwartzmann, J. R. (1948): Follow-up Study of the Early Treatment of Congenital Dislocation of the Hip. Journal of Bone and Joint Surgery, 30-A, 428.

Dickson, F. D. (1935): The Shelf Operation in the Treatment of Congenital Dislocation of the Hip. Journal of Bone and Joint Surgery, 17, 43.

Esteve, R. (1960): Congenital Dislocation of the Hip. Journal of Bone and Joint Surgery, 42-B, 253.

Farrell, B. P., and Howorth, M. B. (1935): Open Reduction in Congenital Dislocation of the Hip. Journal of Bone and Joint Surgery, 17, 35.

Galloway, H. P. H. (1920): The Open Operation for Congenital Dislocation of the Hip. Journal of Orthopaedic Surgery, 2, 390.

GiLl, A. B. (1935): Plastic Construction of an Acetabulum in Congenital Dislocation of the Hip-The Shelf Operation. Journal of Bone and Joint Surgery, 17, 48.

GILL, A. B. (1948): The End Results of Early Treatment of Congenital Dislocation of the Hip. Journal of Bone and Joint Surgery, 30-A, 442.

Groves, E. W. Hey (1928): The Treatment of Congenital Dislocation of the Hip-Joint with Special Reference to Open Operative Reduction. In The Robert Jones Birthday Volume, p. 73. London: Humphrey Milford Oxford University Press.

Hass, J. (1951): Congenital Dislocation of the Hip. Oxford: Blackwell Scientific Publications Ltd.

Kawamura, B. (1959): The Transverse Pelvic Osteotomy. Journal of the Japanese Orthopaedic Society, $32,65$.

LANGENSKIÖID, F. (1953): On the Transposition of the Ileopsoas-Muscle in Operative Reduction of Congenital Hip-Dislocation. Acta Orthopaedica Scandinavica, 22, 295.

Laurent, L. E. (1953): Congenital Dislocation of the Hip. Acta Chirurgica Scandinavica, Supplementum 179.

LeVeuf, J. (1948): Results of Open Reduction of "True " Congenital Luxation of the Hip. Journal of Bone and Joint Surgery, 30-A, 875.

McDonald, J. L. (1934): Personal Communication.

Mackenzie, I. G., Seddon, H. J., and Trevor, D. (1960): Congenital Dislocation of the Hip. Journal of Bone and Joint Surgery, 42-B, 689.

Massie, W. K., and Howorth, M. B. (1951): Congenital Dislocation of the Hip. Part II. Results of Open Reduction as Seen in Early Adult Period. Journal of Bone and Joint Surgery, 33-A, 171.

Muller, G. M., and Seddon, H. J. (1953): Late Results of Treatment of Congenital Dislocation of the Hip. Journal of Bone and Joint Surgery, 35-B, 342.

Pauwels, F. (1951): Des affections de la hanche d'origine mécanique et de leur traitement par l'ostéotomie d'adduction. Revue de Chirurgie Orthopédique, 37, 22.

Pemberton, P. A. (1958): Osteotomy of the Ilium with Rotation of the Acetabular Roof for Congenital Dislocation of the Hip. Proceedings of the American Academy of Orthopaedic Surgeons. Journal of Bone and Joint Surgery, 40-A, 724.

Pemberton, P. A. (1959): Personal communication.

Platou, E. (1953a): Rotation Osteotomy in the Treatment of Congenital Dislocation of the Hip. Journal of Bone and Joint Surgery, 35-A, 48.

Platou, E. (1953b): Luxatio Coxae Congenita. A Follow-up Study of Four Hundred and Six Cases of Closed Reduction. Journal of Bone and Joint Surgery, 35-A, 843.

Platt, Sir H. (1956): Congenital Dislocation of the Hip: the Rôle of Open Reduction. In Modern Trends in Orthopaedics. Second series. Edited by Sir Harry Platt. London: Butterworth \& Co. (Publishers) Ltd.

Ponseti, I. (1944): Causes of Failure in the Treatment of Congenital Dislocation of the Hip. Journal of Bone and Joint Surgery, 26, 775. 
Ponseti, I. (1946): Pathomechanics of the Hip After the Shelf Operation. Journal of Bone and Joint Surgery, 28, 229.

Ponseti, I. V., and Frigerio, E. R. (1959): Results of Treatment of Congenital Dislocation of the Hip. Journal of Bone and Joint Surgery, 41-A, 823.

Putti, V. (1933): Early Treatment of Congenital Dislocation of the Hip. Journal of Bone and Joint Surgery, $15,16$.

Salter, R. B., and Field, P. (1960): The Effects of Continuous Compression on Living Articular Cartilage. An Experimental Investigation. Journal of Bone and Joint Surgery, 42-A, 31.

Schwartz, R. P. (1945): V Plaster Splint for Maintaining Reduction of Congenital Dislocation of the Hip. Journal of Bone and Joint Surgery, 27, 166.

Severin, E. (1941): Contribution to the Knowledge of Congenital Dislocation of the Hip Joint. Acta Chirurgica Scandinavica, 84, Supplementum 63.

Shands, A. R., Jun., and Steele: M. K. (1958): Torsion of the Femur. Journal of Bone and Joint Surgery, 40-A, 803.

Smith-Petersen, M. N. (1917): A new supra-articular subperiosteal approach to the hip joint. American Journal of Orthopedic Surgery, 15, 592.

Somervil Le, E. W. (1953): Open Reduction in Congenital Dislocation of the Hip. Journal of Bone and Joint Surgery, 35-B, 363.

Somerville, E. W., and Scotr, J. C. (1957): The Direct Approach to Congenital Dislocation of the Hip. Journal of Bone and Joint Surgery, 39-B, 623.

TREVOR, D. (1957): Treatment of Congenital Dislocation of the Hip. Journal of Bone andJoint Surgery, 39-B,611.

Trevor, D. (1958): Osteotomy in the Treatment of Congenital Dislocation of the Hip. Proceedings of the Royal Society' of Medicine (Section of Orthopaedics), 51, 1,045.

Wiberg, G. (1939): Studies on Dysplastic Acetabular and Congenital Subluxation of the Hip Joint, with Special Reference to the Complication of Osteo-arthritis. Acta Chirurgica Scandinavica, 83, Supplementum 58.

Wiberg, G. (1953): Shelf Operation in Congenital Dysplasia of the Acetabulum and in Subluxation and Dislocation of the Hip. Journal of Bone and Joint Surgery, 35-A, 65.

Wilkinson, J., and CARTer, C. (1960): Congenital Dislocation of the Hip. Journal of Bone and Joint Surgery, 42-B, 669. 